\title{
DISCURSOS DE LA
}

SEXUALIDAD EN

EL CINE

\section{Presentación}

\section{Coordinadores del número:}

\section{Francisco García García}

\section{Catedrático}

Facultad de Ciencias de la Información. Universidad Complutense de Madrid. Avda. Complutense s/n, 28040 Madrid (España) - Email: fghenche@gmail.com

\section{Miguel Arroyo Fernández}

\section{Investigador}

Facultad de Ciencias de la Información. Universidad Complutense de Madrid. Avda. Complutense s/n, 28040 Madrid (España) - Email: arroyomiguel@movistar.es

\section{Datos del número}

URL: www.icono14.net

Fecha de publicación: 01/07/2011

Director de la revista: Francisco García García (Catedrático de Comunicación Audiovisual y Publicidad de la UCM)

Coordinadores del número: Francisco García García y Miguel Arroyo Fernández (Catedrático e investigador)

\section{Presentación}

El primer asunto que tuvimos que esclarecer fue cuál sería el concepto de "discurso" que propondríamos a la hora de hacer pública la convocatoria para la petición de artículos. La primera intención era organizar un monográfico especializado acerca del "discurso de la sexualidad en el cine".
Según el concepto que se emplea en narrativa audiovisual y siguiendo por ejemplo a Chatman (1990), la "historia" es lo que se cuenta y el "discurso" cómo se cuenta. Es decir, la idea inicial era seleccionar un conjunto de artículos que analizaran la forma en que el lenguaje cinematográfico 
expresa la sexualidad; los procedimientos que, como forma particular de expresión artística, el cine emplea para reflejar esta realidad humana.

Pero pronto nos dimos cuenta de que acudiendo a un concepto menos restrictivo de "discurso", podríamos dar cabida en el monográfico a muchas más inquietudes y posibles líneas de investigación de autores que tal vez no fueran especialistas en narrativa audiovisual, pero que tenían algo que decir acerca de cómo el cine a través de las representaciones que hace de la sexualidad, ejerce una influencia social.

Decidimos entonces adoptar el concepto filosófico de "discurso", tal como lo emplearon entre otros Foucault (1977). En suma, nos interesaban tanto las técnicas que emplea el lenguaje cinematográfico para representar la sexualidad, como la "lucha de discursos" - los distintos puntos de vista ideológicos y morales que el cine transmite acerca de la sexualidad humana y los procesos de cambio social e ideológico en los que el cine participa.

Las líneas de investigación que propusimos fueron deliberadamente amplias, con objeto de que los autores pudieran elegir con libertad alguna de ellas:

1. Aplicaciones del cine para educar a distintos colectivos en valores, así como en habilidades y estrategias que faciliten la convivencia y colaboren en el crecimiento de su bienestar sexual, corporal $\mathrm{y}$ afectivo.
2. Reflejos en el cine de la sexualidad infantil y adolescente. La sexualidad y el cuerpo del niño, la maduración biológica en la pubertad, la iniciación sexual y afectiva.

3. La diferencia sexual: cómo se retratan los distintos estilos de comunicación, intereses, emotividad y estrategias para desenvolverse en la sociedad. Diferencias biológicas y diferencias de género. Pervivencia de los estereotipos sociales.

4. El cuerpo representado en el cine: los modelos de belleza, fealdad, estilización, gordura, juventud o decrepitud. Las zonas tabú del cuerpo.

5. Cine erótico, clasificado "S" y pornográfico. Sus límites, carencias, aplicaciones e influencia social.

6. Humor cinematográfico: el humor que explora los límites sexuales, el que estigmatiza la diferencia, el que se rebela ante las normas sociales, el que refuerza la cohesión del grupo.

7. Las minorías sexuales, la creación de identidades y de fobias sociales (homofobia, bifobia, transfobia, heterofobia)

8. La lucha de los sexos en el cine: representaciones que reflejan la misoginia (odio a la mujer) o la misoandria (odio al hombre). La incomunicación, la violencia sexista, las vías de reconciliación. Los modelos positivos de hombre y de mujer. 
9. Los vínculos afectivos en los discursos cinematográficos: el enamoramiento, el amor, la amistad, los celos, la envidia, la fidelidad y la infidelidad, los apegos sanos y los enfermizos, la formación y ruptura de la pareja. El sexo con y sin amor. La afectividad y sexualidad en la tercera edad.

La respuesta fue calurosa, por la cantidad de autores que se interesaron en participar en el monográfico. Las dieciséis colaboraciones que fueron seleccionadas para su publicación están vinculadas a Universidades españolas. La Complutense y la Carlos III de Madrid, con sus pujantes departamentos de Comunicación Audiovisual son con mucho las que mayores aportaciones han hecho a este monográfico, pero también hemos recibido valiosas colaboraciones de las Universidades de La Laguna, de Valladolid y de Sevilla, así como de la Rey Juan Carlos y la Autónoma de Madrid.

Tras recibir las propuestas de los autores, pudimos comprobar que varias líneas de investigación quedaban inexploradas a pesar de su interés. Nadie se ocupó, al menos como tema central, del cine como posible instrumento para la educación en valores. Tal vez este vacío lo hubiera llenado el eminente psicólogo y sexólogo Julián Fernández de Quero, a quien invitamos a participar pero que por razones personales no pudo finalmente mandarnos su escrito. No obstante, Julián ha publicado recientemente un libro sobre cine y educación de la ciudadanía disponible en la red (Fernández de Quero 2009) que constituye un buen punto de referencia para quienes estén interesados en este asunto.

Tampoco hubo escritos que trataran de forma central el cuerpo representado en el cine, ni el humor sexual cinematográfico, ni los vínculos afectivos y las emociones implicadas en las relaciones amorosas. De todos esos temas se hablaba en los escritos recibidos, pero sólo de forma tangencial.

Los asuntos que atrajeron más atención a lo largo de las más de cuatrocientas páginas que componen el monográfico fueron el de la representación de las minorías sexuales, la incomunicación entre los sexos en la pareja, la crisis de la masculinidad, así como el cine erótico y pornográfico.

Algunos artículos exploraron el cine coreano, iraní y norteamericano. Otros trataron el cine de forma más global incorporando en sus reflexiones cintas de distintas épocas y nacionalidades, pero en su mayor parte los autores optaron por el estudio del cine español. Se observa en este sentido una especie de nostalgia de la Transición, época de cambio entusiasmado en la que el cine en sus distintas vertientes (el de la movida madrileña, el de compromiso político, el erótico...) se implicó activamente en los procesos de cambio social -sin perder por ello su carácter comercial-, dando lugar a algunas de las cintas más originales y relevantes de la historia de nuestro cine. 


\section{Referencias}

Arroyo Fernández, M. (1997) Diccionario de escuelas de pensamiento o ismos. Madrid: Alderabán.

Chatman, S. (1990). Historia y discurso: la estructura narrativa en la novela y el cine. Madrid: Taurus.

García García F. (2006) Narrativa audiovisual. Madrid: Laberinto
Fernández de Quero J. (2009) Cine y educación para la ciudadanía. Descargado el 20 de Agosto del 2011 desde http: / / www.bubok.es / libros / 15304/ cine-yeducacion--para-la-ciudadania

Foucault, Michel (1977). Historia de la sexualidad: 1. La voluntad de saber. Madrid: Siglo XXI

\section{Cita de este artículo}

GARCÍA GARCÍA, F. y ARROYO FERNÁNDEZ, M. (2011).

Discursos de la sexualidad en el cine. Presentación. Revista Icono14 [en línea] 1 de Octubre de 2011, Año 9, Vol. Especial. pp. 01-04. Recuperado (Fecha de acceso), de http://www.icono14.net 